\title{
Evolution of the relationship between total suspended solids concentration and turbidity during flushing sequences of water pipes
}

\author{
Florent Pourcel, Sophie Duchesne and Maxim Ouellet
}

\begin{abstract}
Particle accumulation and circulation in water distribution systems are significant in the development of good management practices to protect against discoloration events, which are a major cause of water customer complaints. Quantifying the amount of particles deposited in water pipes is usually done by obtaining total suspended solid measurements while performing flushing sequences, which requires time, skills, and equipment. Some authors explored the possibility of rapidly approximating total suspended solids concentration (TSSC) in water pipes by measuring water turbidity on site, but they obtained different results and coefficients of correlation. This paper presents the results of tests performed in the laboratory on a test loop. Unidirectional flushing (UDF) and air scouring sequences were performed under various hydraulic conditions and two different particle origins. Samples were obtained along each sequence, and the turbidity and TSSC were measured. The results illustrate that the ratio between turbidity and TSSC may vary greatly between samples, up to 10 times during UDF sequences and 20 times during air scouring sequences. Particle origin, flushing method, and sampling time are all factors impacting the turbidity/TSSC ratio. This is why TSSC should not be estimated from a single turbidity reading.
\end{abstract}

Key words | flushing, particles, total suspended solids, turbidity, water distribution systems

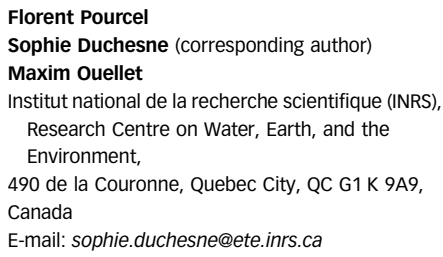

Florent Pourcel

Sophie Duchesne (corresponding author) Maxim Ouellet

Institut national de la recherche scientifique (INRS) Research Centre on Water, Earth, and the Environment,

490 de la Couronne, Quebec City, OC G1 K 9 A9, Canada

E-mail: sophie.duchesne@ete.inrs.ca

\section{INTRODUCTION}

Particle accumulation in water distribution systems (WDSs) is a major concern. When resuspended, accumulated particles can cause a water discoloration event, which is one of the top reasons for customer complaints (Hasit 2004; Vreeburg \& Boxall 2007; Ryan et al. 2008; Cook et al. 20I6). Accumulated particles also cause health concerns by creating a favorable environment for the accumulation of various pollutants, such as heavy metals, toxic organic compounds, and micro-/macro-organism proliferation. During discoloration events, customers may be exposed to all these (Bass \& McCulloch I998; Gauthier I998).

The mechanisms leading to particle accumulation have been identified (Vreeburg \& Boxall 2007). Due to the large variety in causes, it is impossible to completely avoid doi: $10.2166 /$ aqua.2020.127 particle accumulation in water distribution pipes, for any treatment type or any pipe material. Solutions have then been developed for water companies to reduce the rate of particle accumulation, such as pipe lining, corrosion inhibitors, continuous blow-off, or self-cleaning networks, or to remove already accumulated particles, such as unidirectional flushing (UDF) or air scouring (Stephenson I989; Ellison 2003; Vitanage et al. 2004; Vreeburg \& Boxall 2007; Abraham et al. 20I6; Husband \& Boxall 20I6).

Understanding particle circulation, accumulation, and resuspension in WDSs is crucial to accurately plan selfcleaning or optimize human interventions, such as the frequency of UDF. Moreover, knowledge about the evolution of particle characteristics during WDS flushing sequences 
is significant in the design of sampling protocols for the establishment of reliable relationships between turbidity and total suspended solids concentration (TSSC) for a given WDS section. Several models have been developed to predict the water turbidity evolution following an unusual increase in water velocity. One example is the Prediction of Discoloration in Distribution Systems (PODDS) model (Husband \& Boxall 2016), which considers accumulated particles as cohesive layers that are mobilized when the shear stress increases. This model remains the only tool calibrated on trunk mains to predict the increase in turbidity due to an increase in water velocity (Meyers et al. 20I7). Ripl et al. (2010) proposed another model in which particle sedimentation, adsorption, corrosion, mobilization, and advection are taken into consideration when evaluating the increase in turbidity due to water velocity increase. Previous models were calibrated using turbidity measurements and provided results in terms of the units of turbidity (NTU or FNU). However, turbidity is an organoleptic parameter that does not describe water composition in terms of particle concentration as the TSSC can. The TSSC cannot be properly evaluated in the field and has to be measured in the laboratory, which requires time, equipment, and qualified workers (AFNOR 2005; ASTM 2018), while turbidity can be obtained on site in a few seconds by operators. Only a few studies established correlations between TSSC and turbidity from samples collected during UDF (see Table 4), and they obtained various equations, with coefficients of determination, $R^{2}$, ranging from 0.53 to 0.92 (Carrière et al. 2005; Besner et al. 2012). In Carrière et al. (2005) and Besner et al. (20I2), the correlation was obtained using composite samples. To the authors' knowledge, only Ahn et al. (20II) published results concerning the evolution of the relationship between turbidity and TSSC in water distribution pipes during flushing sequences, but they obtained only an average correlation $\left(R^{2}=0.66\right)$, for four pipes from the same WDS.

However, there are numerous studies evaluating such correlations for particles from origins other than WDSs (see Table 4), such as those by Holliday et al. (2003), who worked with soil particles, and Rügner et al. (2013), who worked with river particles. Holliday et al. (2003) concluded that the ratio between turbidity and TSSC is almost 1:1 when working with a silt and clay fraction of soil particles, but that smaller ratios between turbidity and TSSC are observed when working with clay and whole soil fractions. Rügner et al. (20I3) reviewed many studies and concluded that a linear, or close to linear, relation exists between turbidity and TSSC in rivers, with a slope ranging between 1 and 2.5 in most cases. Holliday et al. (2003) and Rügner et al. (2013) both agreed that the main factors influencing the relationship between TSSC and turbidity are particle size, density and shape, type of particles in general, and water color. This could explain the differences in the relations observed in the different studies previously mentioned. Moreover, such relations should not be used with sand-size or larger particles, as the larger the particles are, the higher the underestimation of the TSSC is from the turbidity measurement since the bigger particles quickly settle and are not monitored by the turbidimeter (Holliday et al. 2003). This leads to major concerns when working with WDS particles. Indeed, as particles can be a mix of filtration media, pipe corrosion products, flocs, and biofilm (Gauthier I998), they have variable characteristics depending on the pipe material, water treatment technology, and water physicochemical composition. However, size, shape, and density are factors impacting the movement of particles when the water velocity increases (Le Hir 2008). Particles could remain motionless, move by saltation or rolling, or be fully resuspended and thus require very variable amounts of time to reach the pipe's outlet.

In this context, it can be hypothesized that the relationship between turbidity and TSSC in water distribution pipes is influenced by the particle origin and flushing conditions, and that this relation evolves during flushing sequences. The main objective of this study is to verify this hypothesis in order for water companies to adopt good practices. In order to do so, the turbidity and TSSC of water samples taken during WDS flushing sequences were studied. These samples were obtained during UDF and air scouring performed under various conditions and with particles of two different origins on a laboratory test loop.

\section{MATERIALS AND METHODS}

To simulate WDS flushing sequences in laboratory conditions, a test loop made of a $150 \mathrm{~mm}$ PVC pipe fouled 
with WDS particles was used. This loop was designed to recreate UDF and air scouring under various conditions. By using a diphasic flow known as slug flow, air scouring permits a higher water velocity and thus a much higher shear stress (Ellison 2003). There are multiple advantages to working with such a loop:

- Several tests can be performed under identical conditions to reinforce the results.

- PVC pipes do not release corrosion products (such as tubercles) as opposed to certain metallic pipes or equipment in real WDSs, such as valves or the hydrant itself. Thus, it is possible to precisely determine the amount and composition of the particles to be flushed.

- The exact geometry of the pipes is known, whereas real WDSs may include unknown bends or uncertain slopes or depths.

The test loop is illustrated in Figure 1 . The $150 \mathrm{~mm}$ pipe is $48 \mathrm{~m}$ long, with a $2 \%$ rising slope.

The water flow rate was measured with an Endress + Hauser Proline Promag $50 \mathrm{~W}$ flowmeter. The air flow was measured by a Cole Parmer Valved Acrylic Flowmeter 400-3400 LPM. The turbidity was measured with a Hach 2100Q turbidimeter, and the TSSC was measured following the filtration method described by AFNOR (2005). Water samples were collected during the flushing sequences from a tap located on the pipeline (see Figure 1).

The loop works in two different modes: fouling and flushing. The fouling mode is performed by recirculating water enriched by WDS particles from a recirculation tank. It is conducted by recirculating fouling water enriched by particles at a velocity of $0.1 \mathrm{~m} \cdot \mathrm{s}^{-1}$, which is a common daily flow velocity in WDSs, as observed by Ahn et al. (20II). Preliminary tests showed that 6 days of continuous recirculation allowed $98-99 \%$ of the particle mass to be accumulated on the pipe wall within the loop. The fouling water was created by enriching tap water with particles collected from WDSs by two means:

- Flushed water was collected in tanks during the UDF of cast iron pipes and subsequently concentrated by sedimentation.

- Tubercles from old cast iron pipes from Quebec City (Canada) were collected and then ground into powder.

Flushed water and tubercle powder were mixed $50 \% \mathrm{~m} / \mathrm{m}$. The first series of tests were conducted with flushed water collected from Sainte-Émélie-de-l'Énergie (Canada) (SEE). Subsequently, a second series was conducted with flushed

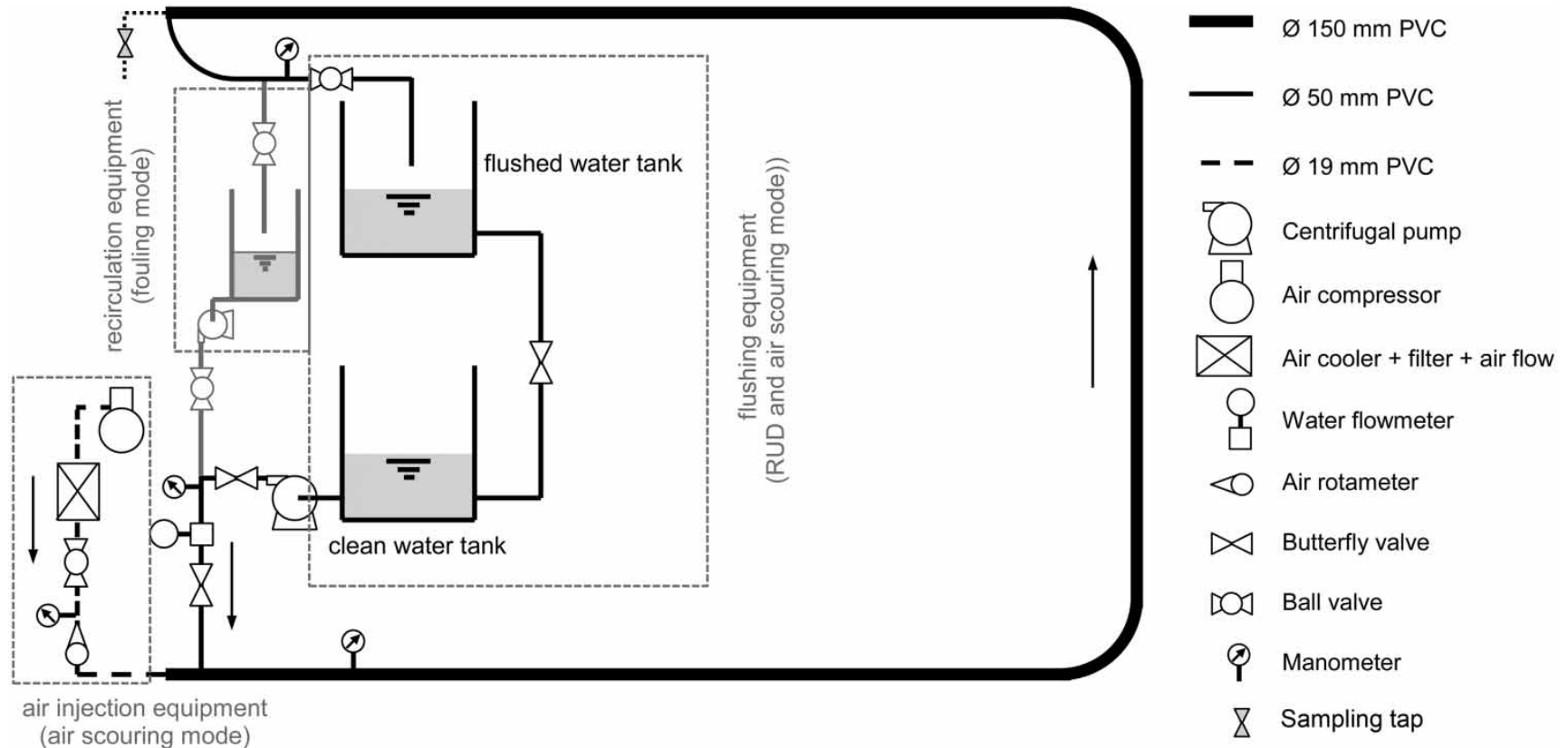

Figure 1 | Test loop diagram. 
water collected from Joliette (Canada). The flushing conditions were similar, and the tubercle powder was identical in both series. The available amount in each series was allowed to foul the pipe 12 times, up to $3.2 \mathrm{~g}_{\mathrm{TSS}} \cdot \mathrm{m}^{-1}$, which corresponds to a moderate annual accumulation as established by Carrière et al. (2005).

Figure S1 and Table S1, in the Supplementary Material section, provide the grain size distribution and chemical composition of each component of the fouling water. Table 1 presents the characteristics of the fouling solutions that were directly introduced into the test loop, after mixing the tubercle powder and flushed water. These numbers are the means of the characteristics of each of the 12 solutions for each series of tests. The observed ratios between turbidity and TSSC, varying from 1.074 to 2.243 NTU.L.mg ${ }^{-1}$, correspond to the range of ratios in the studies reported in the introduction for river water.

After 6 continuous days of fouling, flushing was performed by pumping clean tap water from one tank and collecting the flushed water in a second tank. During each flushing sequence, 20 samples of flushed water were collected to measure turbidity and TSSC. Tests were run on loop under six different hydraulic conditions: two recreating UDF and four recreating air scouring, all of them in duplicate with both SEE and Joliette flushed water. Table 2 summarizes the hydraulic conditions during each test.

Before fouling the test loop to perform the following flushing test, particles from the previous test were removed by swabbing the loop two times.

\section{RESULTS AND DISCUSSION}

Figure 2 depicts the evolution of the turbidity/TSSC ratio during the flushing sequences until the turbidity becomes

Table 1 | Fouling solution characteristics

\begin{tabular}{|c|c|c|}
\hline & $\begin{array}{l}\text { SEE fouling } \\
\text { solution }\end{array}$ & $\begin{array}{l}\text { Joliette fouling } \\
\text { solution }\end{array}$ \\
\hline Turbidity (NTU) & $137 \pm 30.7$ & $303 \pm 31.5$ \\
\hline $\operatorname{TSSC}\left(\mathrm{mg} \cdot \mathrm{L}^{-1}\right)$ & $127 \pm 25.5$ & $136 \pm 18.5$ \\
\hline Turbidity/TSSC (NTU.L.mg ${ }^{-1}$ ) & $1.08 \pm 0.09$ & $2.24 \pm 0.22$ \\
\hline
\end{tabular}

Table 2 | Hydraulic conditions during test loop experiments

\begin{tabular}{|c|c|c|c|}
\hline $\begin{array}{l}\text { Flushing method } \\
\text { simulated }\end{array}$ & $\begin{array}{l}\text { Water superficial } \\
\text { velocity }\left(\mathbf{m} \cdot \mathbf{s}^{-1}\right)\end{array}$ & $\begin{array}{l}\text { Air superficial } \\
\text { velocity }\left(\mathbf{m} \cdot \mathbf{s}^{-1}\right)\end{array}$ & $\begin{array}{l}\text { Shear } \\
\text { stress }^{\text {a }}(\mathrm{Pa})\end{array}$ \\
\hline \multirow[t]{2}{*}{ UDF } & 1.0 & - & 2.4 \\
\hline & 1.9 & & 7.7 \\
\hline \multirow[t]{4}{*}{ Air scouring } & 0.3 & 1.8 & 18.0 \\
\hline & 0.6 & 5.1 & 68.0 \\
\hline & 0.3 & 4.6 & 62.0 \\
\hline & 0.6 & 2.3 & 30.0 \\
\hline
\end{tabular}

${ }^{a}$ For UDF and air scouring, shear stress was estimated from the Darcy-Weisbach formula using a $0.05 \mathrm{~mm}$ roughness. For air scouring, the slugs' average velocity was computed using Bendiksen's (1984) equations, and the shear stress estimated with the Darcy-Weisbach formula was increased by $35 \%$, as measured by Kaul (1996) in slugs' mixing zones. Air scouring is based on slug flow, which implies, in particular, that water slugs have variable velocities; thus, the maximum shear stress during a sequence could be higher.

lower than 5 NTU. The horizontal axis is the ratio between the flushing water volume and the pipe volume. Figure S2 in the Supplementary Material includes, as an example, the evolution of the turbidity and TSSC values for four of the tests (the other tests show similar behaviors). Sequences often stop when the flushing water volume reaches approximately 2-3 times the pipe volume for UDF, which is the value reported in the literature to get turbidity lower than 5 NTU (Ellison 2003). For air scouring, except for the tests performed at low shear stress (water $0.3 \mathrm{~m} \cdot \mathrm{s}^{-1}$ and air 1.8 $\left.\mathrm{m} \cdot \mathrm{s}^{-1}\right)$, low turbidity values $(<5 \mathrm{NTU})$ are generally obtained when the flushing water volume reaches approximately 1.5 times the pipe volume; this means that air scouring requires less water volume than does UDF to get a similar turbidity, which is also reported in the literature (Ellison 2003; Vitanage et al. 2004).

The results in Figure 2 show that the mean relative variation of the turbidity/TSSC ratio between its maximum, which is always observed at the beginning of the sequences, and minimum values is 10.2 with a standard deviation of 11.3 for UDF and 25.3 with a standard deviation of 22.0 for air scouring. The greater variations of the turbidity/ TSSC ratio during air scouring sequences, as compared to UDF, are probably due to the fact that a wider range of particle diameters are removed during these sequences than during UDF sequences. One should note however that the observed variations in the turbidity/TSSC ratio could have been different if the diameter and slope of the test loop had been varied. 

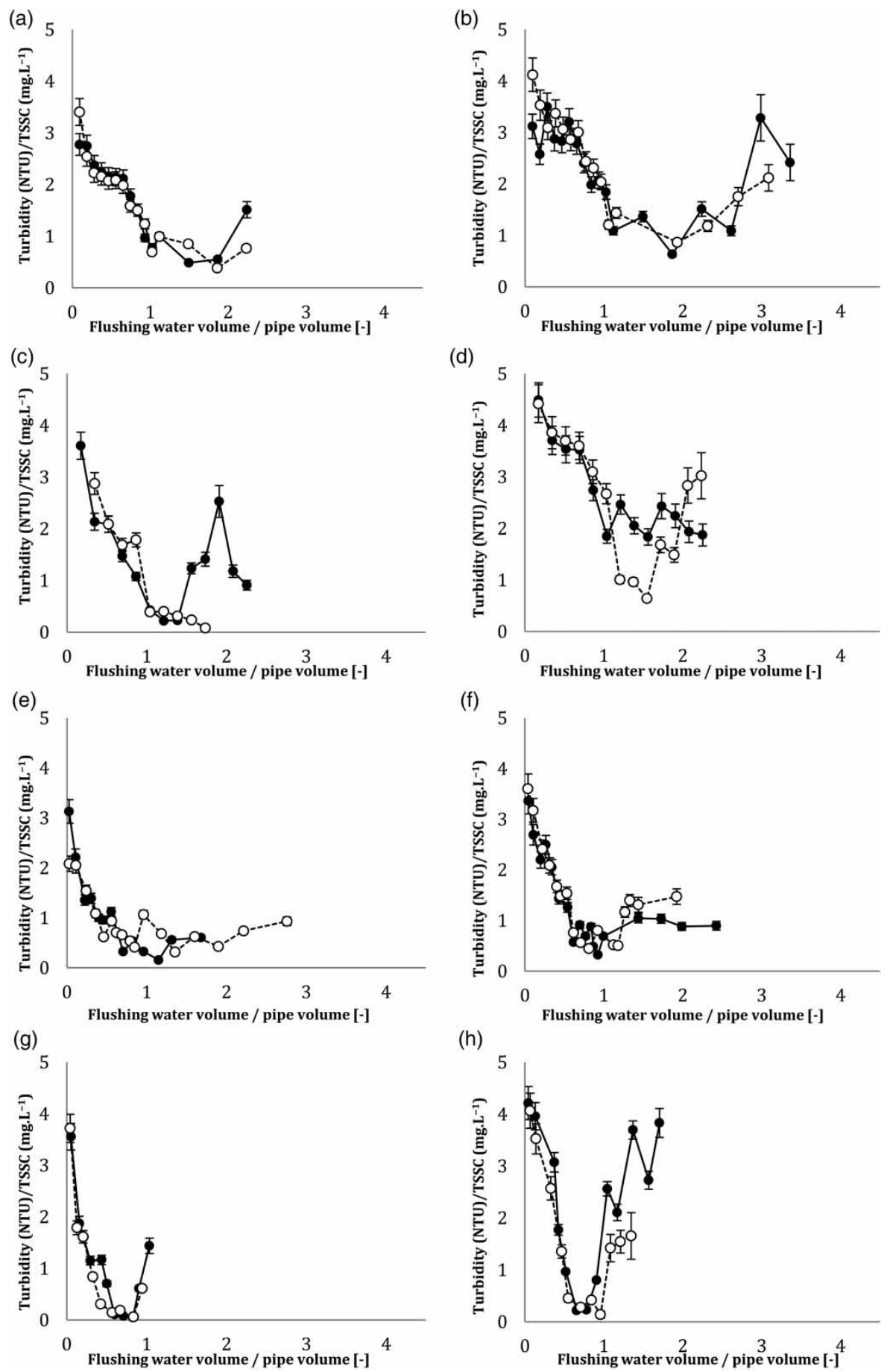

Figure 2 | Evolution of the ratio of turbidity versus TSSC along flushing sequences (left side $(a, c, e, g, i, k)=S E E$ particles; right side (b, d, f, h, j, l) = Joliette particles; a and b: UDF $1 \mathrm{~m} \cdot \mathrm{s}^{-1}$; $\mathrm{c}$ and d: UDF $1.9 \mathrm{~m} \cdot \mathrm{s}^{-1}$; e and f: air scouring with water $0.3 \mathrm{~m} \cdot \mathrm{s}^{-1}$ and air $1.8 \mathrm{~m} \cdot \mathrm{s}^{-1} ; \mathrm{g}$ and h: air scouring with water $0.6 \mathrm{~m} \cdot \mathrm{s}^{-1}$ and air $5.1 \mathrm{~m} \cdot \mathrm{s}^{-1} ; \mathrm{i}$ and $\mathrm{j}$ : air scouring with water $0.3 \mathrm{~m} \cdot \mathrm{s}^{-1}$ and air $4.6 \mathrm{~m} \cdot \mathrm{s}^{-1} ; \mathrm{k}$ and $\mathrm{l}$ : air scouring with water $0.6 \mathrm{~m} \cdot \mathrm{s}^{-1}$ and air $2.3 \mathrm{~m} \cdot \mathrm{s}^{-1}$ ); filled and hollow circles represent each of the two tests performed under the same conditions. (Continued).

All the curves display a similar evolution of the relationship between turbidity and TSSC along the flushing sequences, with an L-shape and sometimes a U-shape. In fact, a U-shape is always observed if the curves are extended to greater values 

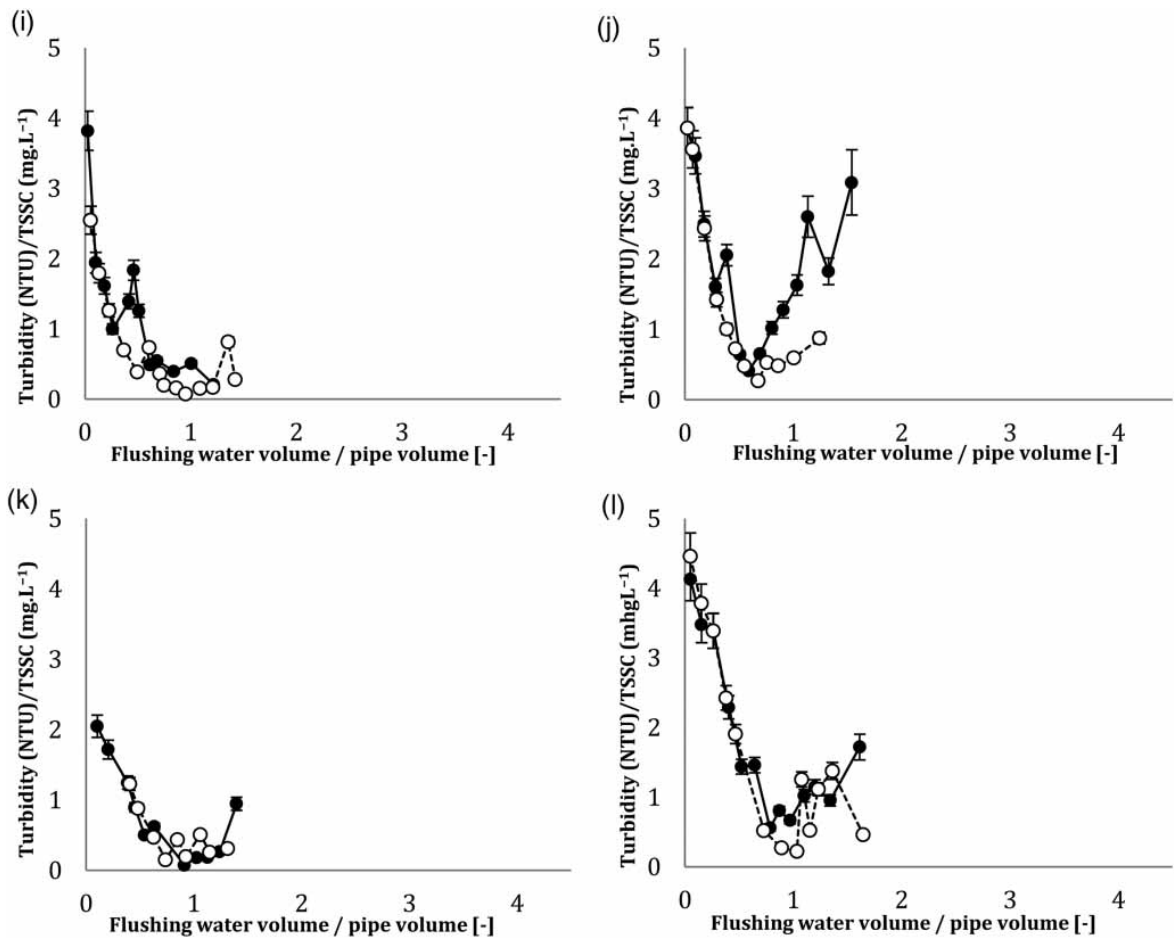

Figure 2 | Continued.

of flushing water volumes (results not presented herein). These shapes make it possible to divide the curves into two parts:

- The first part exhibits a continuous decrease in the turbidity/TSSC ratio (part 1).

- The second part corresponds to the ratio at its minimum values, followed by an ascent of the ratio, when it exists (part 2).

The point of separation between these two parts is the point from which the decreasing trend between the turbidity and TSSC becomes less significant. A Mann-Kendall test was used to identify this point for each series. More specifically, for each series, a Mann-Kendall test was performed successively for various subsets, all starting from the first sample and ending sequentially at the second, third, and fourth samples, until the last one. The end point of the subset exhibiting the lowest $p$-value for the Mann-Kendall test was considered to be the breaking point separating the two parts of the curve. The results are summarized in Table 3 . Among the 24 sequences performed, only the 6 indicated in gray, identified the last sample as the breaking point.
These results indicate that the turbidity/TSSC ratio evolves significantly along the flushing sequences, dropping by $90 \%$ almost linearly during two pipe volumes for UDF sequences and by $95 \%$ during one pipe volume for air scouring sequences. Subsequently, there is a significant change in the slope, which could eventually become positive. The wide range in particle sizes, including larger particles, as shown in Figure S1, could explain this evolution. Indeed, larger particles require a higher shear stress to be set into motion, and the largest move more slowly, by a mix of suspension, saltation, and rolling (Le Hir 2008), and thus require a longer time to reach the outlet of the pipe. As the larger particles arrive at the outlet, the turbidity/TSSC ratio decreases. A higher shear stress during the air scouring sequences could cause the larger particles to move faster and thus the breaking point to occur earlier and the relative variation between the maximum and the minimum values of the turbidity/TSSC ratio to present a wider distribution. The positive slope, at the end of part 2, could be explained by the presence of very small particles stuck on the wall by weak interactions such as electrostatic or van 
Table 3 Breaking point identified with the Mann-Kendall tests (gray cells are for the sequences for which the last sample was identified as the breaking point)

\begin{tabular}{|c|c|c|c|}
\hline Origin & Test conditions & $\begin{array}{l}\text { Breaking point } \\
\text { (flushing water } \\
\text { volume/pipe } \\
\text { volume) }\end{array}$ & $p$-value \\
\hline \multirow[t]{12}{*}{ SEE } & \multirow[t]{2}{*}{ UDF $1.0 \mathrm{~m} \cdot \mathrm{s}^{-1}$} & 1.87 & $4.25 \times 10^{-6}$ \\
\hline & & 2.23 & $3.29 \times 10^{-6}$ \\
\hline & \multirow[t]{2}{*}{ UDF $1.9 \mathrm{~m} \cdot \mathrm{s}^{-1}$} & 1.39 & $1.98 \times 10^{-3}$ \\
\hline & & 1.74 & $1.23 \times 10^{-3}$ \\
\hline & \multirow{2}{*}{$\begin{array}{l}\text { Air scouring water } \\
0.3 \mathrm{~m} \cdot \mathrm{s}^{-1} \text { air } 1.8 \mathrm{~m} \cdot \mathrm{s}^{-1}\end{array}$} & 1.15 & $1.62 \times 10^{-4}$ \\
\hline & & 0.96 & $6.77 \times 10^{-4}$ \\
\hline & \multirow{2}{*}{ Air scouring water } & 0.83 & $1.98 \times 10^{-3}$ \\
\hline & & 0.83 & $1.98 \times 10^{-3}$ \\
\hline & Air scouring water & 1.22 & $7.79 \times 10^{-4}$ \\
\hline & $0.3 \mathrm{~m} \cdot \mathrm{s}^{-1}$ air $4.6 \mathrm{~m} \cdot \mathrm{s}^{-1}$ & 1.09 & $1.86 \times 10^{-4}$ \\
\hline & \multirow{2}{*}{ Air scouring water } & 1.24 & $4.21 \times 10^{-3}$ \\
\hline & & 1.03 & $4.43 \times 10^{-2}$ \\
\hline \multirow[t]{12}{*}{ Joliette } & \multirow[t]{2}{*}{ UDF $1 \mathrm{~m} \cdot \mathrm{s}^{-1}$} & 2.61 & $8.97 \times 10^{-5}$ \\
\hline & & 2.32 & $7.15 \times 10^{-5}$ \\
\hline & \multirow[t]{2}{*}{ UDF $1.9 \mathrm{~m} \cdot \mathrm{s}^{-1}$} & 2.25 & $1.22 \times 10^{-3}$ \\
\hline & & 1.55 & $2.63 \times 10^{-4}$ \\
\hline & \multirow{2}{*}{$\begin{array}{l}\text { Air scouring water } \\
\quad 0.3 \mathrm{~m} \cdot \mathrm{s}^{-1} \text { air } 1.8 \mathrm{~m} \cdot \mathrm{s}^{-1}\end{array}$} & 1.00 & $4.36 \times 10^{-5}$ \\
\hline & & 1.18 & $7.32 \times 10^{-5}$ \\
\hline & \multirow{2}{*}{$\begin{array}{l}\text { Air scouring water } \\
0.6 \mathrm{~m} \cdot \mathrm{s}^{-1} \text { air } 5.1 \mathrm{~m} \cdot \mathrm{s}^{-1}\end{array}$} & 0.78 & $6.86 \times 10^{-3}$ \\
\hline & & 0.96 & $1.98 \times 10^{-3}$ \\
\hline & \multirow{2}{*}{$\begin{array}{l}\text { Air scouring water } \\
\quad 0.3 \mathrm{~m} \cdot \mathrm{s}^{-1} \text { air } 4.6 \mathrm{~m} \cdot \mathrm{s}^{-1}\end{array}$} & 0.59 & $6.86 \times 10^{-3}$ \\
\hline & & 0.68 & $8.37 \times 10^{-4}$ \\
\hline & \multirow{2}{*}{$\begin{array}{l}\text { Air scouring water } \\
\quad 0.6 \mathrm{~m} \cdot \mathrm{s}^{-1} \text { air } 2.3 \mathrm{~m} \cdot \mathrm{s}^{-1}\end{array}$} & 1.02 & $2.50 \times 10^{-3}$ \\
\hline & & 1.03 & $8.37 \times 10^{-4}$ \\
\hline \multicolumn{2}{|c|}{ UDF mean } & \multicolumn{2}{|l|}{2.00} \\
\hline \multicolumn{2}{|c|}{ Standard deviation for UDF } & 0.42 & \\
\hline \multicolumn{2}{|c|}{ Air scouring mean } & 1.00 & \\
\hline \multicolumn{2}{|c|}{$\begin{array}{l}\text { Standard deviation for air } \\
\text { scouring }\end{array}$} & 0.22 & \\
\hline
\end{tabular}

der Waals forces (Jürgen 2004), thereby requiring a longer time for removal.

Figures 3(a) and 3(b) illustrate that samples taken during the tests conducted with Joliette's particles seem to exhibit an overall higher turbidity/TSSC ratio than the ones performed with the SEE's particles. In addition, samples taken after the slope's breaking point (in part 2) are grouped at the bottom of the graphs, indicating the highest TSSC as compared to turbidity in this case. In Figure 4(a), samples taken during tests carried out at $1.9 \mathrm{~m} \cdot \mathrm{s}^{-1}$ seem to give an overall higher turbidity/TSSC ratio than the ones performed at $1.0 \mathrm{~m} \cdot \mathrm{s}^{-1}$ for TSSCs of approximately $100 \mathrm{mg} \cdot \mathrm{L}^{-1}$ and higher. There is no obvious trend displayed in Figure 4(b). This could be due to the following hypothesis: particle origins, flushing methods, flushing conditions, and sampling before or after the breaking point impact the slope between the turbidity and TSSC. To test this hypothesis, Kruskall-Wallis (KW) and analysis of variance (ANOVA) tests were performed with the turbidity/TSSC ratio for all samples as the independent variable. The null hypotheses tested stated that 'the data in each group have the same distribution' for the KW test and that 'the data in each group have the same mean' for the ANOVA test. The turbidity/TSSC data were categorized, depending on the tested parameter: two groups for particle origin (SEE or Joliette), two groups for flushing method (UDF or air scouring), six groups for flushing conditions (refer to Table 2 for condition descriptions), and two groups for part of the curve (before or after the breaking point). For both tests, obtaining a $p$-value below 0.05 means

Table 4 | Relationships between TSSC and turbidity as established by various authors with particles of different origins

\begin{tabular}{|c|c|c|c|}
\hline & Particles origin & Equation & $R^{2}$ \\
\hline Ahn et al. (20II) & Seoul WDS (South Korea) & $\mathrm{TSS}=0.6405 \mathrm{NTU}+3.6166$ & $0.66^{\mathrm{a}}$ \\
\hline Besner et al. (2012) ${ }^{\mathrm{b}}$ & Waterloo WDS (ON, Canada) & $\operatorname{Ln}(\mathrm{TSS})=0.5968 \operatorname{Ln}(\mathrm{NTU})+1.0232$ & 0.53 \\
\hline Carrière et al. $(2005)^{\mathrm{b}}$ & WDS from three Canadian cities & $\begin{array}{l}\mathrm{TS}=0.94 \mathrm{NTU}^{0.87} \\
\quad(\mathrm{TS}=\text { total solids })\end{array}$ & 0.92 \\
\hline \multirow[t]{3}{*}{ Holliday et al. (2003) } & $\begin{array}{l}\text { Whole soil } \\
\text { Southeastern Piedmont soil }\end{array}$ & $\mathrm{NTU}=0.4822 \mathrm{TSS}^{1.012}$ & 0.9987 \\
\hline & Clay fraction & $\mathrm{NTU}=0.7733 \mathrm{TSS}^{0.9336}$ & 0.9996 \\
\hline & Silt + clay fraction & $\mathrm{NTU}=1.0283 \mathrm{TSS}^{1.0282}$ & 0.9991 \\
\hline Rügner et al. (2013) & Various rivers in normal conditions (review) & $\begin{array}{l}\text { A linear regression with a correlation coefficient ranging } \\
\text { from } 1 \text { to } 2.5 \mathrm{mg} \cdot \mathrm{L}^{-1} \cdot \mathrm{NTU}^{-1}\end{array}$ & N/A \\
\hline
\end{tabular}

${ }^{a}$ Correlation computed by removing one experimental point considered as an outlier.

${ }^{\mathrm{b}}$ From composite samples collected over the first 10-min period of each flushing sequence. 

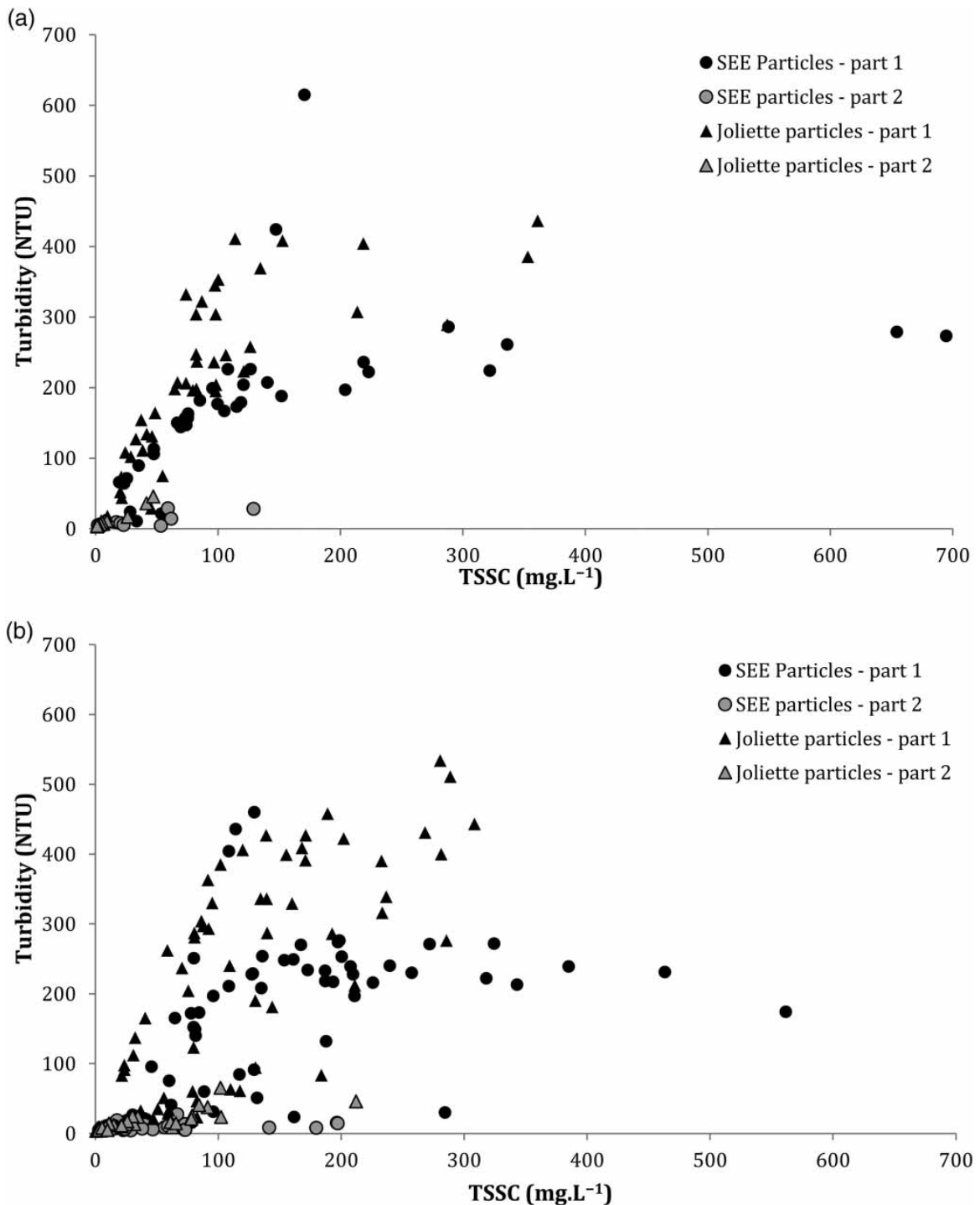

Figure 3 Turbidity versus TSSC in parts 1 and 2 of the curves shown in Figure 2 for (a) UDF sequences and (b) air scouring sequences.

that the null hypothesis is rejected at a $5 \%$ level of significance. The results are presented in Table 5. To validate these tests, a preliminary Fisher test confirmed that all groups have different variances, and a Kolmogorov-Smirnov test confirmed that all groups follow a normal distribution with a $5 \%$ significance level.

The resultant $p$-values were all below 0.05 except for the flushing conditions for both UDF and air scouring. This indicates that the particle origin and the flushing method significantly influence the relationship between TSSC and turbidity, but that the flushing conditions do not. The parameter 'part of the curve' shows that the KW and ANOVA tests validate that the moment the sample is taken (during the first or second part of the curve) also has to be considered.

\section{CONCLUSIONS}

The main findings of this study from air scouring and UDF tests performed in a PVC pipe test loop are that:

- the ratio between turbidity and TSSC is shown to vary between samples during a flushing sequence, up to 10 times for UDF and up to 20 times for air scouring, which means that turbidity is not correlated with TSSC, 

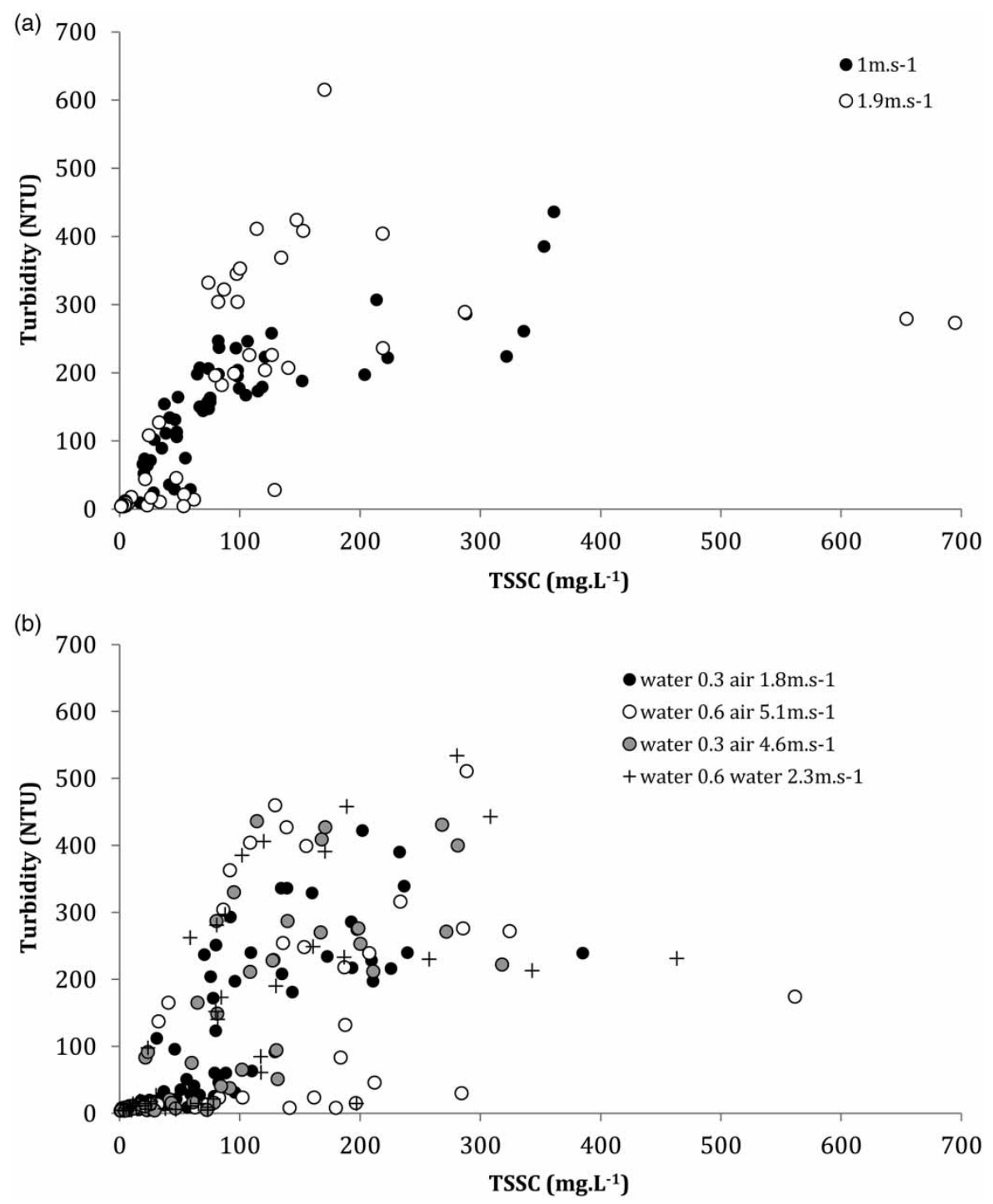

Figure 4 | Turbidity versus TSSC depending on flushing conditions for (a) UDF sequences and (b) air scouring sequences.

Table 5 | $p$-values of KW and ANOVA tests considering the turbidity/TSSC ratio as the dependent variable

\begin{tabular}{lllll} 
& Particles origin & Flushing method & UDF flushing conditions & Air scouring flushing conditions \\
\hline KW & $8.92 \times 10^{-6}$ & $9.38 \times 10^{-9}$ & $9.05 \times 10^{-1}$ & $9.07 \times 10^{-1}$ \\
ANOVA & $4.70 \times 10^{-6}$ & $1.20 \times 10^{-7}$ & $9.44 \times 10^{-1}$ & $3.54 \times 10^{-1}$ \\
\hline
\end{tabular}

- the particle origin (the type of water), flushing method (air scouring or UDF), and sampling time are all factors impacting the turbidity/TSSC ratio, and

- however, the flushing conditions (water velocity, for both air scouring and UDF, and air velocity, for air scouring) do not have a significant impact on the mean turbidity/ TSSC ratio.

In light of these findings, it seems unrealistic to establish a universal equation that provides an estimation of TSSC from 
turbidity readings during water pipes flushing for all WDS and even for a specific pipe. Indeed, this ratio could vary greatly during a flushing sequence. This is why WDS managers should avoid estimating TSSC from a single turbidity reading. Even though some previous studies did show some correlations between TSSC and turbidity, these were generally established in other contexts than WDS flushing (e.g. for river water) and/or over wide ranges of TSSC and turbidity values (e.g. from around 1-1,000 NTU for turbidity), for which the lowest TSSC values were not well represented by the correlation model, and/or using composite samples.

It should be noted that the results obtained in this study could be different in the presence of a mature biofilm on the pipe wall. However, investigating this would have required extending the fouling step over a period much longer than 6 days. The next step should compare these results to those obtained from the similar work performed on real WDSs. The corrosion of pipes and other cast iron parts, such as hydrants and valves, or the presence of tubercles, may impact particle circulation and accumulation, which should be investigated.

\section{SUPPLEMENTARY MATERIAL}

The Supplementary Material for this paper is available online at https://dx.doi.org/10.2166/aqua.2020.127.

\section{ACKNOWLEDGEMENTS}

The authors thank Mitacs and Nordikeau for their financial support to this project. The authors are also grateful to the two anonymous reviewers whose comments helped improve the quality of the paper.

\section{REFERENCES}

Abraham, E., Blokker, E. J. M. \& Stoianov, I. 2016 Network analysis, control valve placement and optimal control of flow velocity for self-cleaning water distribution systems. Procedia Engineering 186, 576-583.

AFNOR 2005 Qualité de l'eau - Dosage des matières en suspension - Méthode par filtration sur filtres en fibres de verre (Water Quality - Determination of Suspended Solids Filtration Method Using Fiberglass Filters). Association française de normalisation, Saint-Denis, France.

Ahn, J. C., Lee, S. W., Choi, K. Y., Koo, J. Y. \& Jang, H. J. 2011 Application of unidirectional flushing in water distribution pipes. Journal of Water Supply: Research and Technology 60 (1), 40-50.

ASTM 2018 ASTM D5907-18, Standard Test Methods for Filterable Matter (Total Dissolved Solids) and Nonfilterable Matter (Total Suspended Solids) in Water. ASTM International, West Conshohocken, PA.

Bass, J. A. B. \& McCulloch, I. D. 1998 Maintaining Awareness of Animals in Distribution Systems. Institute of Freshwater Ecology, East Stoke, UK.

Bendiksen, K. H. I984 An experimental investigation of the motion of long bubbles in inclined tubes. International Journal of Multiphase Flow 10 (4), 467-483.

Besner, M. C., Modak, P. R. \& Glauser, N. 2012 Extensive sediment characterization during unidirectional flushing in a distribution system. In: 14th Water Distribution Systems Analysis Conference, September 24-27, 2012. Engineers Australia and American Society of Civil Engineers, Adelaide, Australia, pp. 871-876.

Carrière, A., Gauthier, V., Desjardins, R. \& Barbeau, B. 2005 Evaluation of loose deposits in distribution systems through unidirectional flushing. Journal of the American Water Works Association 97 (9), 82-92.

Cook, D. M., Husband, S. \& Boxall, J. B. 2016 Operational management of trunk main discolouration risk. Urban Water Journal 13 (4), 382-395.

Ellison, D. 2003 Investigation of Pipe Cleaning Methods. AWWA Research Foundation and American Water Works Association, Denver, CO. p. 142.

Gauthier, V. 1998 Les particules dans les réseaux d'eau potable: caractérisation et impact sur la qualité de l'eau distribuée (Particles in Drinking Water Systems: Characterization and Impact on Distributed Water Quality). PhD Thesis, Henry Poincare University, Nancy, France.

Hasit, Y. J. 2004 Cost and Benefit Analysis of Flushing. AWWA Research Foundation, American Water Works Association, Denver, CO, p. 110.

Holliday, C. P., Rasmussen, T. C. \& Miller, W. P. 2003 Establishing the relationship between turbidity and total suspended sediment concentration. In: Georgia Water Resources Conference (K. J. Hatcher, ed.). University of Georgia, Athens, GA.

Husband, S. \& Boxall, J. B. 2016 Understanding and managing discolouration risk in trunk mains. Water Research 107, 127-140.

Jürgen, T. 2004 Mechanics of Particle Adhesion. Department of Process Engineering and Systems Engineering, Otto-vonGuericke University, Magdeburg, Germany, p. 92.

Kaul, A. 1996 Study of Slug Flow Characteristics and Performance of Corrosion Inhibitors, in Multiphase Flow, in Horizontal Oil and Gas Pipelines. PhD Thesis, Ohio University, Athens, $\mathrm{OH}$, p. 99. 
Le Hir, P. 2008 Aide mémoire de dynamique sédimentaire (Reference Guide for Sediment Dynamics). PHYSED Laboratory, IFREMER Center, Plouzane, France.

Meyers, G., Kapelan, Z. \& Keedwell, E. 2017 Short-term forecasting of turbidity in trunk main networks. Water Research 124, 67-76.

Ripl, K., Slavik, I. \& Uhl, W. 20Io Classification of drinking water pipe sections with respect to particle related water quality. In: 12th Annual Conference on Water Distribution Systems Analysis - WDSA 2010, September 12-15, 2010, Tucson, AZ, pp. 955-967.

Rügner, H., Schwientek, M., Beckingham, B., Kuch, B. \& Grathwohl, P. 2013 Turbidity as a proxy for total suspended solids (TSS) and particle facilitated pollutant transport in catchments. Environmental Earth Sciences 69 (2), 373-380.
Ryan, G., Mathes, P., Haylock, G., Jayaratne, A., Wu, J., Noui-Mehidi, N., Grainger, C. \& Nguyen, B. V. 2008 Particles in Water Distribution Systems. The Cooperative Research Centre for Water Quality and Treatment, Salisbury, Australia, p. 106.

Stephenson, G. I989 Removing Loose Deposits From Water Mains: Operational Guidelines. Water Research Centre, Swindon, UK, p. 53.

Vitanage, D., Pamminger, F. \& Vourtsanis, T. 2004 Maintenance and survey of distribution systems. In: Safe Piped Water: Managing Microbial Water Quality in Piped Distribution Systems (R. Ainsworth, ed.). World Health Organization and IWA Publishing, London, UK, pp. 70-85.

Vreeburg, J. H. \& Boxall, J. B. 2007 Discolouration in potable water distribution systems: a review. Water Research 41 (3), 519-529.

First received 11 September 2019; accepted in revised form 17 February 2020. Available online 26 March 2020 